\title{
HER2 expression and relevant clinicopathological features in esophageal squamous cell carcinoma in a Chinese population
}

\section{Lulu Rong}

National Cancer Center/National Clinical Research Center for Cancer/Cancer Hospital, Chinese Academy of Medical Sciences and Peking Union Medical College

\section{Bingzhi Wang}

National Cancer Center/National Clinical Research Center for Cancer/Cancer Hospital, Chinese Academy of Medical Sciences and Peking Union Medical College

\section{Lei Guo}

National Cancer Center/National Clinical Research Center for Cancer/Cancer Hospital, Chinese Academy of Medical Sciences and Peking Union Medical College

Xiuyun Liu

National Cancer Center/National Clinical Research Center for Cancer/Cancer Hospital, Chinese Academy of Medical Sciences and Peking Union Medical College

\section{Bingning Wang}

National Cancer Center/National Clinical Research Center for Cancer/Cancer Hospital, Chinese Academy of Medical Sciences and Peking Union Medical College

Jianming Ying

National Cancer Center/National Clinical Research Center for Cancer/Cancer Hospital, Chinese Academy of Medical Sciences and Peking Union Medical College

\section{Liyan Xue ( $\nabla$ xuely@cicams.ac.cn )}

Department of Pathology and Resident Training Bass, National Cancer Center/Cancer hospitial, Chinese Academy of Medical Sciences and Peking Union Medical College, Beijing, China

\section{Ning Lu}

National Cancer Center/National Clinical Research Center for Cancer/Cancer Hospital, Chinese Academy of Medical Sciences and Peking Union Medical College

\section{Research article}

Keywords: HER2, esophageal squamous cell carcinoma, dual-color in situ hybridization, clinicopathological characteristics

Posted Date: August 28th, 2019 
DOI: https://doi.org/10.21203/rs.2.13291/v1

License: (c) (1) This work is licensed under a Creative Commons Attribution 4.0 International License. Read Full License

Version of Record: A version of this preprint was published at Diagnostic Pathology on March 24th, 2020. See the published version at https://doi.org/10.1186/s13000-020-00950-y. 


\section{Abstract}

Background: Despite great progress of surgery and other treatments, the prognosis of patients with esophageal squamous cell carcinoma (ESCC) is still very poor. HER2 has strong therapeutic implications in certain cancers, such as breast cancer and gastric cancer. However, literature on the frequency of HER2 expression in ESCC is scarce. In the present study, HER2 expression and gene amplification and the association of HER2 status with clinicopathological characteristics were evaluated in a large cohort of Chinese ESCC patients.

Methods: A total of 857 consecutive patients who received radical esophagectomy without neoadjuvant chemotherapy were included in this retrospective study. HER2 expression was analyzed by immunohistochemistry $(\mathrm{IHC})$, and its correlation with clinicopathological parameters was assessed. In addition, 65 cases, including 13 HER2 overexpression (3+) cases and 52 HER2 equivocal (2+) cases from the 857-case cohort, were selected to construct tissue microarrays (TMAs). Another 104 ESCC cases, which included 1 HER2 overexpression (3+) case, 3 HER2 equivocal (2+) cases and 100 HER2 negative $(1+/ 0)$ cases, were also selected for TMA construction. Dual-color in situ hybridization (DISH) was performed on the TMAs to assess HER2 gene amplification.

Results: We found HER2 overexpression (3+) status in 1.5\% (13/857) of cases and HER2 equivocal (2+) status in $6.1 \%(52 / 857)$ of cases. HER2 expression was significantly associated with gender. HER2 equivocal (2+) expression was more likely to occur in females $(P=0.028)$. Regarding the 169 cases analyzed by DISH, 14 (of 14, 100\%) HER2 overexpression (3+) cases, 10 (of 55, 18.2\%) HER2 equivocal (2+) cases, and 0 (of $100,0 \%$ ) HER2 negative $(1+/ 0)$ cases showed HER2 gene amplification. HER2 gene amplification was not significantly associated with clinicopathological characteristics such as age, gender, tumor differentiation, $\mathrm{pT}$ stage, $\mathrm{pN}$ stage, $\mathrm{pM}$ stage and pTNM stage $(\mathrm{P}>0.05)$.

Conclusions: Approximately $2 \%$ of the Chinese ESCC patients had HER2 overexpression based on IHC. HER2 expression was significantly associated with gender, HER2 gene amplification was not significantly associated with clinicopathological characteristics. IHC and DISH had a high concordance rate. These results provide valuable insight for the future treatment of ESCC.

\section{Background}

Esophageal cancer, one of the most common human cancer types, is difficult to cure unless it is found at an early stage. Esophageal squamous cell carcinoma (ESCC) is the 3rd most common cause of death from cancer in China[1]. Despite great progress in surgery and other treatments, the prognosis of ESCC patients is still very poor. Therefore, new therapies, particularly targeted therapies, are urgently needed to improve the survival rate and survival quality for ESCC patients[2].

The HER2 proto-oncogene (c-erbB-2), which is located on chromosome 17, has drawed much attention because of its therapeutic implications. HER2 is a type I transmembrane tyrosine kinase growth factor receptor that recognizes as a key factor in the processes of tumor cell proliferation, differentiation and 
growth[3]. Based on various immunohistochemistry (IHC) scoring criteria and patient cohorts, wide ranges of HER2-positive expression rates have been reported in breast cancer, gastric cancer, lung cancer and colon cancer. HER2 has been confirmed as an important role in many human cancers, especially breast cancer[4].

Few studies of HER2 protein expression and gene amplification in ESCC have been conducted to date, and varying results have been reported for HER2 status in ESCC[5-7]. However, the clinicopathological features associated with HER2 protein expression and gene amplification have not been fully elucidated.

The aims of this study were to evaluate HER2 protein expression by IHC and to detect HER2 gene amplification by dual-color in situ hybridization (DISH) in a large cohort of Chinese ESCC patients. Moreover, the correlation with clinicopathological parameters was analyzed.

\section{Methods}

\section{Samples}

A total of 857 consecutive patients who received radical esophagectomy without neoadjuvant chemotherapy at the National Cancer Center/National Clinical Research Center for Cancer/Cancer Hospital, Chinese Academy of Medical Sciences and Peking Union Medical College between January 2014 and October 2015 were included in this retrospective study. HER2 expression was evaluated by IHC. Moreover, 65 cases, including 13 HER2 overexpression (3+) cases and 52 HER2 equivocal (2+) cases, from the 857-case cohort were selected for the construction of tissue microarrays (TMAs). Another 104 ESCC cases between January 2008 and May 2009, which included 1 HER2 overexpression (3+) case, 3 HER2 equivocal $(2+)$ cases and 100 HER2 negative $(1+/ 0)$ cases, were also selected to construct TMAs. DISH was performed on TMAs to evaluate HER2 gene amplification. In addition, patient medical records and clinicopathological parameters were reviewed, including age at diagnosis, gender, tumor differentiation, and PTNM stage, which was assessed according to the 8th American Joint Committee on Cancer (AJCC) TNM classification[8].

\section{Immunohistochemistry}

Automated IHC was performed on 4- $\mu$ m-thick sections using a Ventana Benchmark XT system (Ventana Medical Systems, Tucson, AZ, USA), an automated slide stainer, and the Ventana CONFIRM ${ }^{\mathrm{TM}}$ rabbit antiHER2/neu (4B5) monoclonal antibody. As standardized scoring criteria for ESCC have not been established or recommended, HER2 IHC results were scored using the HER2 scoring criteria for breast cancer as follows: 0 , no staining or weak, partial membranous staining in $\leq 10 \%$ of tumor cells; $1+$, weak/almost imperceptible membranous staining in $>10 \%$ of tumor cells; $2+$, weak to moderate partial membranous staining in $>10 \%$ of tumor cells or strong and complete membranous staining in $\leq 10 \%$ of tumor cells; and $3+$, complete, balanced membranous reactivity of strong intensity in $>10 \%$ of tumor cells[9]. 
In determining the HER2 status, cases with HER2 negative expression were defined by scores of 0 or $1+$, whereas cases with HER2 overexpression were defined by scores of $3+$. Cases with moderate expression (2+) were considered as HER2 equivocal expression.

\section{Dual-color in situ hybridization}

DISH was performed with a BenchMark XT Staining Platform (Ventana Medical Systems, Tucson, AZ) using an INFORM HER2 Dual ISH DNA Probe Assay and $5-\mu \mathrm{m}$ tissue sections. The kit contains two DNA probes, the Inform ${ }^{\circledR}$ ErbB2 DNA Probe (labeled with black) and the Inform ${ }^{\circledR}$ Chromosome 17 Probe (CEP17) (labeled with red). DISH signals were observed using conventional light microscope. The HER2/CEP17 ratio was assessed using the scoring criteria of fluorescence in situ hybridization (FISH) for breast cancer[9]. The HER2 and CEP17 signals were counted in 20 tumor cell nuclei in two different areas. HER2 gene amplification was quantitatively assessed by evaluating the HER2/CEP17 ratio and the average number of HER2 signals in each cell. The "amplified" was assigned if the HER2/CEP17 ratio was $\geq 2.0$ or if the HER2/CEP17 ratio was $<2.0$ but the average number of HER2 signals in each cell was $\geq 6.0$. Conversely, the designation "not amplified" was given if the HER2/CEP17 ratio was $<2.0$ and the average number of HER2 signals was $<4.0$. When a case had a HER2/CEP17 signal count ratio of $<2.0$ and an average number of HER2 signals per cell of $\geq 4.0$ and $<6.0$, signals were counted in another 20 nuclei, and the result was determined in a total of 40 tumor cell nuclei.

\section{TMA construction}

TMAs were constructed from three 1.5-mm cores of tumor tissue from each case using a Manual Tissue Arrayer (MTA-1, Beecher Instruments, Silver Spring, MD).

\section{Statistical analysis}

SPSS 19.0 software was used for the statistical analyses. The significance of differences between HER2 status and clinicopathological parameters was assessed by the chi-square test, and $P<0.05$ was considered to indicate a statistically significant difference.

\section{Results}

\section{HER2 IHC expression and clinicopathological characteristics}

The cohort of 857 ESCC patients was analyzed by IHC. The median age of the 857 patients was 60.94 years (range 37-81 years), with a male predominance (83.1\%). Among the 857 patients, the tumors were spindle cell differentiation in $3(0.4 \%)$, basaloid differentiation in $36(4.2 \%)$, poor differentiation in 241 
(28.1\%), moderate differentiation in 469 (54.7\%), and well differentiation in 105 (12.3\%). Regarding the pT stage, most patients were at stage T3 (54.6\%), with $22.2 \%, 16.9 \%$, and $6.3 \%$ at stages T1, T2, and T4, respectively. Moreover, $50.6 \%, 27.4 \%, 17.4 \%$, and $4.6 \%$ of the cases were at stages N0, N1, N2, and N3, respectively. Distant metastases were not found in the majority of patients $(99.9 \%)$ at surgery (Table 1).

Of the 857 cases, $13(1.5 \%)$ were scored as HER2 overexpression (3+), with $52(6.1 \%)$ and $792(92.4 \%)$ scored as equivocal $(2+)$ and negative $(1+/ 0)$, respectively. HER2 expression was significantly correlated with gender $(P=0.028)$. HER2 equivocal $(2+)$ expression was more likely to occur in females. No correlation between HER2 expression and age, tumor differentiation, pT stage, pN stage, pM stage and pTNM stage was observed ( $P>0.05)$ (Table 1) (Figure 1).

\section{HER2 gene amplification and clinicopathological characteristics}

DISH analysis was performed for 169 ESCC cases, including 14 HER2 overexpression (3+) cases, 55 HER2 equivocal $(2+)$ cases, and 100 HER2 negative $(1+/ 0)$ cases. HER2 amplification was observed in 14 (of $14,100 \%$ ) HER2 overexpression (3+) cases, 10 (of 55, 18.2\%) HER2 equivocal (2+) cases, and 0 (of $100,0 \%)$ HER2 negative (1+/0) cases. HER2 gene amplification was not significantly associated with clinicopathological characteristics such as age, gender, tumor differentiation, pT stage, pN stage, pM stage and pTNM stage ( $P>0.05)$ (Table 2$)$.

\section{Concordance between HER2 IHC and DISH}

A high concordance rate of $100 \%$ was observed between IHC and DISH (Table 3) (Figure 2).

\section{Discussion}

In the current study, IHC revealed 13 of $857(1.5 \%)$ consecutive ESCC cases to have a status of HER2 overexpression (3+) and 52 of $857(6.1 \%)$ to have a status of HER2 equivocal expression (2+). Dreilich and colleagues found that among 70 ESCC patients, $1.4 \%$ were HER2 positive expression (3+)[10]. Nig et al. found that the HER2 overexpression (3+) and HER2 equivocal expression (2+) rates were $1.5 \%$ and $5.9 \%$ in 68 ESCC patients, respectively[11], similar to our results. However, HER2 overexpression in ESCC has been reported in several studies to range from $1 \%$ to $10.4 \%[5-7,10-17]$. These differences might be due to several factors, including antibodies, cut-off points, IHC methods or neoadjuvant therapy. In a study by Shibata-Kobayashi et al., the HER2 positivity rate was $10 \%$ among 10 ESCC cases treated with concurrent chemoradiation therapy (CCRT), and the level of HER2 expression was assessed using the immunoreactive scoring (IRS) system[16]. However, Akamatsu et al. found that CCRT had an effect on HER2 expression in ESCC patients[17]. Therefore, in the present study, we selected ESCC esophagectomy samples without CCRT, the possible effect on HER2 expression of which was excluded. 
The relationship between HER2 IHC expression and the clinicopathologic characteristics of patients with ESCC is controversial based on data from previous studies. Chen et al. reported that HER2 expression levels were associated with gender, tumor size and venous/lymphatic invasion[18]. We also showed that HER2 expression was associated with gender and found that HER2 equivocal (2+) expression was more likely to occur in female patients $(11.0 \%)$ than in male patients $(5.1 \%)$. In addition, we did not find that tumor differentiation was associated with HER2 overexpression, which was reported by Zhan et al.[5]. In contrast, Gonzaga et al. and Sato-Kuwabara et al. revealed that there was no correlation between HER2 expression and clinicopathological parameters[2,7]. Moreover, we found there was no significant association between HER2 gene amplification and clinicopathological characteristics, but in Zhan et al.'s study, HER2 gene amplification was associated with tumor differentiation and tumor stage[5]. Further studies are necessary to better understand the significance of HER2 gene amplification in ESCC patients.

In studies by Gonzaga et al., Mimura et al. and Sato-Kuwabara et al., all the HER2 overexpression (3+) cases exhibited gene amplification[2,6,7], and we obtained the same finding. Schoppmann et al. used DISH to show that 8 of 9 HER2 overexpression (3+) cases showed amplification, their study included biopsy samples and surgically resected specimens, and thus, heterogeneity in HER2 expression might have influenced the results[13,19]. In our study, 10 of 55 (18.2\%) HER2 equivocal (2+) cases showed gene amplification. Mimura et al. found 3 of $6(50 \%)$ HER2 equivocal (2+) cases with gene amplification[6], but Gonzaga et al. and Sato-Kuwabara et al. reported no gene amplification among HER2 equivocal (2+) cases[2,7]. In Zhan et al.'s study, HER2 amplification cases included all 15 HER2 overexpression (3+) cases and 6 of $45(13.3 \%)$ HER2 equivocal (2+) cases[5]. In contrast, Sunpaweravong et al. found 5 HER2 positive expression (2+) cases showed no gene amplification and 1 HER2 negative expression cases showed gene amplification, there was no association between HER2 gene amplification and HER2 protein expression[20]. Based on our results, IHC and DISH have a high concordance rate, and HER2 overexpression among our cases was caused by gene amplification.

Most studies have analyzed HER2 gene amplification using FISH, whereas we employed DISH to evaluate HER2 gene amplification. This approach is useful for HER2 gene testing and is recommended as a new option for assessing HER2 status. Indeed, a high concordance between DISH and FISH for evaluating HER2 gene amplification in breast cancer has been reported[21]. Moreover, another study showed that DISH had better quality and reproducibility, the results could be observed using conventional microscopy, allowing pathologists to simultaneously assess HER2 gene status and tissue morphology, which is not possible with FISH[22].

HER2 gene amplification occurs in approximately $15 \%$ to $20 \%$ of breast cancers[23]. HER2 status evaluated by in situ hybridization (ISH) or IHC are the primary predictors of responsiveness to HER2targeted therapies and determine the benefit from adjuvant trastuzumab therapy in breast cancer[24]. Moreover, HER2 is the only validated biomarker for selecting gastroesophageal adenocarcinoma patients who might benefit from targeted therapy[25], and trastuzumab is able to prolong overall survival in gastroesophageal adenocarcinoma patients with HER2 overexpression[26,27]. Similarly, ESCC patients with HER2 gene amplification might also benefit from trastuzumab treatment[12]. HER2 has recently 
been reported as an effective response predictor for HER2 targeted therapy in ESCC patients, and ESCC patients with HER2 overexpression might benefit from HER2-targeted therapy[3,19,28,29]. In this study, we utilized IHC and DISH to analyze HER2 status, and our findings provided valuable information for the treatment of ESCC.

\section{Conclusions}

Approximately $2 \%$ of the Chinese ESCC patients had HER2 overexpression based on IHC. HER2 expression was significantly associated with gender, HER2 gene amplification was not significantly associated with clinicopathological characteristics. IHC and DISH had a high concordance rate. These results provide valuable insight for the future treatment of ESCC.

\section{Abbreviations}

ESCC: esophageal squamous cell carcinoma; IHC: immunohistochemistry; TMAs: tissue microarrays; DISH: dual-color in situ hybridization; AJCC: American Joint Committee on Cancer; CEP17: Chromosome 17 Probe; FISH: fluorescence in situ hybridization; CCRT: concurrent chemoradiation therapy; IRS: immunoreactive scoring system.

\section{Declarations}

\section{Ethics approval and consent to participate}

This study was conducted after approval by the Ethics Committee from National Cancer Center/National Clinical Research Center for Cancer/Cancer Hospital, Chinese Academy of Medical Sciences and Peking Union Medical College. The consent was not required from each patient because this was a retrospective study. Tumour tissues of this study were achieved from the archival paraffin blocks of the repository of Department of Pathology, National Cancer Center/National Clinical Research Center for Cancer/Cancer Hospital, Chinese Academy of Medical Sciences and Peking Union Medical College. All procedures were performed in line with the declaration of Helsinki's version of 1983.

\section{Consent for publication}

Not applicable.

\section{Availability of data and materials}

The datasets used and analyzed during the current study are available from the corresponding author on reasonable request. 


\section{Competing interests}

The authors declare that there is no conflict of interest regarding the publication of this article.

\section{Funding}

This work was supported by the National Natural Science Foundation of the Peoples' Republic of China (No. 81402463), the CAMS Innovation Fund for Medical Sciences (CIFMS) (Grant No. 2016-I2M-1-001 and 2016-12M-3-005) and the Non-profit Central Research Institute Fund of the Chinese Academy of Medical Sciences (2016ZX310178, 2017PT32001 and 2018PT32012).

\section{Authors' contributions}

LLR, LYX and NL: Designing the project and writing the paper. LG, XYL: analyzing and interpreting the data. BZW, BNW and JMY: performing the data collection and revising the manuscript critically. All authors read and approved the final manuscript.

\section{Acknowledgements}

Not applicable.

\section{References}

1.Torre LA, Bray F, Siegel RL, Ferlay J, Lortet-Tieulent J, Jemal A. Global cancer statistics, 2012. CA: A Cancer Journal for Clinicians. 2015;65:87-108.

2.Gonzaga IM, Soareslima SC, de Santos PT, Blanco TC, de Reis BS. Alterations in epidermal growth factor receptors 1 and 2 in esophageal squamous cell carcinomas. BMC Cancer. 2012; 12: 569.

3.Fichter CD, Gudernatsch V, Przypadlo CM, Follo M, Schmidt G, Werner M, et al. ErbB targeting inhibitors repress cell migration of esophageal squamous cell carcinoma and adenocarcinoma cells by distinct signaling pathways. J Mol Med (Berl). 2014;92:1209-23.

4.Shan L, Ying J, Lu N. HER2 expression and relevant clinicopathological features in gastric and gastroesophageal junction adenocarcinoma in a Chinese population. DIAGN PATHOL. 2013;8:76.

5.Zhan N, Dong W, Tang Y, Wang Z, Xiong C. Analysis of HER2 gene amplification and protein expression in esophageal squamous cell carcinoma. MED ONCOL. 2012;29:933-40.

6.Mimura K, Kono K, Hanawa M, Mitsui F, Sugai H, Miyagawa N, et al. Frequencies of HER-2/neu expression and gene amplification in patients with oesophageal squamous cell carcinoma. $\mathrm{Br} \mathrm{J}$ Cancer. 
7.Sato-Kuwabara Y, Neves JI, Fregnani JH, Sallum RA, Soares FA. Evaluation of gene amplification and protein expression of HER-2/neu in esophageal squamous cell carcinoma using Fluorescence in situ Hybridization (FISH) and immunohistochemistry. BMC CANCER. 2009;9:6.

8.Rice TW, Gress DM, Patil DT, Hofstetter WL, Kelsen DP, Blackstone EH. Cancer of the esophagus and esophagogastric junction-Major changes in the American Joint Committee on Cancer eighth edition cancer staging manual. CA Cancer J Clin. 2017;67:304-17.

9. Wolff AC, Hammond ME, Hicks DG, Dowsett M, McShane LM, Allison KH, et al. Recommendations for human epidermal growth factor receptor 2 testing in breast cancer: American Society of Clinical Oncology/College of American Pathologists clinical practice guideline update. J CLIN ONCOL. 2013;31:3997-4013.

10.Dreilich M, Wanders A, Brattstrom D, Bergstrom S, Hesselius P, Wagenius G, et al. HER-2 overexpression (3+) in patients with squamous cell esophageal carcinoma correlates with poorer survival. DIS ESOPHAGUS. 2006;19:224-31.

11.NIG AMK, REEH M, DANCAU A, RATHJENS M, GROS S. Concordance of HER2 Status in Primary Tumour and Lymph Node Metastases in Patients with Esophageal Carcinoma. Anticancer Res. 2013; 33: 4975-82.

12.Kawaguchi Y, Kono K, Mimura K, Mitsui F, Sugai H, Akaike H, et al. Targeting EGFR and HER-2 with cetuximab- and trastuzumab-mediated immunotherapy in oesophageal squamous cell carcinoma. $\mathrm{Br} \mathrm{J}$ Cancer. 2007;97:494-501.

13.Schoppmann SF, Jesch B, Friedrich J, Wrba F, Schultheis A, Pluschnig U, et al. Expression of Her-2 in carcinomas of the esophagus. AM J SURG PATHOL. 2010;34:1868-73.

14.Gibault L, Metges JP, Conan-Charlet V, Lozac'H P, Robaszkiewicz M, Bessaguet C, et al. Diffuse EGFR staining is associated with reduced overall survival in locally advanced oesophageal squamous cell cancer. Br J Cancer. 2005;93:107-15.

15.Hatogai K, Fujii S, Kojima T, Daiko H, Nomura S, Doi T, et al. Large-scale comprehensive immunohistochemical biomarker analyses in esophageal squamous cell carcinoma. J Cancer Res Clin Oncol. 2017;143:2351-61.

16.Shibata-Kobayashi S, Yamashita H, Okuma K, Shiraishi K, Igaki H, Ohtomo K, et al. Correlation among 16 biological factors [p53, p21 (waf1), MIB-1 (Ki-67), p16(INK4A), cyclin D1, E-cadherin, Bcl-2, TNFalpha, NF-kappaB, TGF-beta, MMP-7, COX-2, EGFR, HER2/neu, ER, and HIF-1alpha] and clinical outcomes following curative chemoradiation therapy in 10 patients with esophageal squamous cell carcinoma. ONCOL LETT. 2013;5:903-10. 
17.Akamatsu M, Matsumoto T, Oka K, Yamasaki S, Sonoue H, Kajiyama Y, et al. c-erbB-2 oncoprotein expression related to chemoradioresistance in esophageal squamous cell carcinoma. International Journal of Radiation Oncology*Biology*Physics. 2003;57:1323-7.

18.CHEN Y, ZHU S, XU X, ZHAO AN, HU J. Expression levels of HER2 and MRP1 are not prognostic factors of long-term survival in 829 patients with esophageal squamous cell carcinoma. 2016;11:745-52.

19.Fazlollahi L, Remotti HE, luga A, Yang HM, Lagana SM, Sepulveda AR. HER2 Heterogeneity in Gastroesophageal Cancer Detected by Testing Biopsy and Resection Specimens. ARCH PATHOL LAB MED. 2018;142:516-22.

20.Sunpaweravong P, Sunpaweravong S, Puttawibul P, Mitarnun W, Zeng C, Baron AE, et al. Epidermal growth factor receptor and cyclin D1 are independently amplified and overexpressed in esophageal squamous cell carcinoma. J Cancer Res Clin Oncol. 2005;131:111-9.

21. Horii R, Matsuura M, Iwase T, Ito Y, Akiyama F. Comparison of dual-color in-situ hybridization and fluorescence in-situ hybridization in HER2 gene amplification in breast cancer. BREAST CANCER-TOKYO. 2014;21:598-604.

22.Fusco N, Bosari S. HER2 aberrations and heterogeneity in cancers of the digestive system: Implications for pathologists and gastroenterologists. World J Gastroenterol. 2016;22:7926-37.

23.Krishnamurti U, Silverman JF. HER2 in breast cancer: a review and update. ADV ANAT PATHOL. 2014;21:100-7.

24. Wolff AC, Hammond MEH, Allison KH, Harvey BE, Mangu PB, Bartlett JMS, et al. Human Epidermal Growth Factor Receptor 2 Testing in Breast Cancer: American Society of Clinical Oncology/College of American Pathologists Clinical Practice Guideline Focused Update. Journal of clinical oncology: official journal of the American Society of Clinical Oncology. 2018:02018778738.

25.Bartley AN, Washington MK, Colasacco C, Ventura CB, Ismaila N, Benson AR, et al. HER2 Testing and Clinical Decision Making in Gastroesophageal Adenocarcinoma: Guideline From the College of American Pathologists, American Society for Clinical Pathology, and the American Society of Clinical Oncology. J CLIN ONCOL. 2017;35:446-64.

26.Bang YJ, Van Cutsem E, Feyereislova A, Chung HC, Shen L, Sawaki A, et al. Trastuzumab in combination with chemotherapy versus chemotherapy alone for treatment of HER2-positive advanced gastric or gastro-oesophageal junction cancer (TOGA): a phase 3, open-label, randomised controlled trial. LANCET. 2010;376:687-97.

27.Kasper S, Schuler M. Targeted therapies in gastroesophageal cancer. EUR J CANCER. 2014;50:124758. 
28.Mimura K, Izawa S, Siba S, Maruyama T, Watanabe M, Kawaguchi Y, et al. [The effect of immunebased therapy with cytotoxic T lymphocyte and molecular targeting therapy for HER2 in esophageal squamous cell carcinoma]. Gan To Kagaku Ryoho. 2011;38:1918-20.

29.Zhang L, Ma J, Han Y, Liu J, Zhou W, Hong L, et al. Targeted therapy in esophageal cancer. Expert Rev Gastroenterol Hepatol. 2016;10:595-604.

\section{Tables}

Table 1: Correlation between HER2 expression status and clinicopathological parameters 


\begin{tabular}{|c|c|c|c|c|c|}
\hline Clinicopathologic feature & Overall & $\begin{array}{l}\text { HER2 } \\
\text { overexpression }\end{array}$ & $\begin{array}{l}\text { HER2 } \\
\text { equivocal }\end{array}$ & $\begin{array}{l}\text { HER2 } \\
\text { negative }\end{array}$ & $P$ value \\
\hline Total & $\mathrm{n}=857$ & $\mathrm{n}=13(1.5 \%)$ & $\mathrm{n}=52(6.1 \%)$ & $\mathrm{n}=792(92.4 \%)$ & \\
\hline Age at diagnosis & & & & & 0.835 \\
\hline$\geq 60$ years & 512 & $8(1.6)$ & $29(5.7)$ & $475(92.8)$ & \\
\hline$<60$ years & 345 & $5(1.4)$ & $23(6.7)$ & $317(91.9)$ & \\
\hline Gender & & & & & 0.028 \\
\hline Male & 712 & $11(1.5)$ & $36(5.1)$ & $665(93.4)$ & \\
\hline Female & 145 & $2(1.4)$ & $16(11.0)$ & $127(87.6)$ & \\
\hline Tumor differentiation & & & & & $0.203^{\square}$ \\
\hline Well & 105 & $0(0.0)$ & $2(1.9)$ & 103(98.1) & \\
\hline Moderate & 469 & $6(1.3)$ & $31(6.6)$ & $432(92.1)$ & \\
\hline Poor & 241 & $6(2.5)$ & $16(6.6)$ & $219(90.9)$ & \\
\hline Basaloid & 36 & $1(2.8)$ & $2(5.6)$ & $33(91.7)$ & \\
\hline Spindle cell & 3 & $0(0.0)$ & $1(33.3)$ & $2(66.7)$ & \\
\hline Basaloid + spindle cell & 3 & $0(0.0)$ & $0(0.0)$ & $3(100)$ & \\
\hline pT status & & & & & 0.584 \\
\hline pT1 & 190 & $5(2.6)$ & $15(7.9)$ & $170(89.5)$ & \\
\hline pT2 & 145 & $2(1.4)$ & $6(4.1)$ & $137(94.5)$ & \\
\hline pT3 & 468 & $6(1.3)$ & $27(5.8)$ & $435(92.9)$ & \\
\hline pT4 & 54 & $0(0.0)$ & $4(7.4)$ & $50(92.6)$ & \\
\hline pN status & & & & & 0.221 \\
\hline pNO & 434 & $5(1.2)$ & $27(6.2)$ & $402(92.6)$ & \\
\hline pN1 & 235 & $6(2.6)$ & $11(4.7)$ & $218(92.8)$ & \\
\hline $\mathrm{pN} 2$ & 149 & $2(1.3)$ & $8(5.4)$ & 139(93.3) & \\
\hline pN3 & 39 & $0(0.0)$ & $6(15.4)$ & $33(84.6)$ & \\
\hline pM status & & & & & NA \\
\hline pMO & 856 & $13(1.5)$ & $52(6.1)$ & $791(92.4)$ & \\
\hline pM1 & 1 & $0(0.0)$ & $0(0.0)$ & $1(100)$ & \\
\hline
\end{tabular}




\begin{tabular}{lllll} 
pTNM stage & & & & \\
I & 166 & $2(1.2)$ & $13(7.8)$ & $151(91.0)$ \\
II & 274 & $5(1.8)$ & $16(5.8)$ & $253(92.3)$ \\
III & 360 & $6(1.7)$ & $15(4.2)$ & $339(94.2)$ \\
IV & 57 & $0(0.0)$ & $8(14.0)$ & $49(86.0)$ \\
\hline
\end{tabular}

प: excluding spindle cell squamous carcinoma and basaloid squamous carcinoma + spindle cell squamous carcinoma

NA, not associated.

Table 2: Correlation between HER2 gene amplification status and clinicopathological parameters 


\begin{tabular}{|c|c|c|c|c|}
\hline Clinicopathologic feature & Overall & $\begin{array}{l}\text { HER2 } \\
\text { DISH (+) }\end{array}$ & $\begin{array}{l}\text { HER2 } \\
\text { DISH (-) }\end{array}$ & $P$ value \\
\hline Total & $\mathrm{n}=169$ & $\mathrm{n}=24(14.2 \%)$ & $\mathrm{n}=145(85.8 \%)$ & \\
\hline Age at diagnosis & & & & 0.660 \\
\hline$\geq 60$ years & 88 & $14(15.9)$ & $74(84.1)$ & \\
\hline$<60$ years & 81 & $10(12.3)$ & $71(87.7)$ & \\
\hline Gender & & & & 1.000 \\
\hline Male & 138 & $20(14.5)$ & $118(85.5)$ & \\
\hline Female & 31 & $4(12.9)$ & $27(87.1)$ & \\
\hline Tumor differentiation & & & & $0.346^{\square}$ \\
\hline Well & 17 & $1(5.9)$ & $16(94.1)$ & \\
\hline Moderate & 91 & $12(13.2)$ & $79(86.8)$ & \\
\hline Poor & 54 & $9(16.7)$ & $45(83.3)$ & \\
\hline Basaloid & 6 & $2(33.3)$ & $4(66.7)$ & \\
\hline Spindle cell & 1 & $0(0.0)$ & $1(100.0)$ & \\
\hline pT status & & & & 0.183 \\
\hline pT1 & 27 & $7(25.9)$ & $20(74.1)$ & \\
\hline pT2 & 21 & $2(9.5)$ & 19(90.5) & \\
\hline pT3+T4 & 121 & $15(12.4)$ & 106(87.6) & \\
\hline pN status & & & & 0.765 \\
\hline pNO & 81 & $12(14.8)$ & $69(85.2)$ & \\
\hline pN1 & 48 & $8(16.7)$ & $40(83.3)$ & \\
\hline pN2 & 26 & $2(7.7)$ & $24(92.3)$ & \\
\hline pN3 & 14 & $2(14.3)$ & $12(85.7)$ & \\
\hline pM status & & & & NA \\
\hline pM0 & 169 & $24(14.2)$ & $145(85.8)$ & \\
\hline pM1 & 0 & $0(0.0)$ & $0(0.0)$ & \\
\hline pTNM stage & & & & 0.858 \\
\hline I & 22 & $4(18.2)$ & 18(81.8) & \\
\hline
\end{tabular}




\begin{tabular}{llll} 
II & 65 & $10(15.4)$ & $55(84.6)$ \\
III & 66 & $8(12.1)$ & $58(87.9)$ \\
IV & 16 & $2(12.5)$ & $14(87.5)$ \\
\hline
\end{tabular}

$\square$ : excluding spindle cell squamous carcinoma

NA, not associated.

Table 3: Correlation between HER2 expression and gene amplification in esophageal squamous cell carcinoma

\begin{tabular}{lllll}
\hline \multirow{2}{*}{ DISH } & \multicolumn{3}{c}{ IHC } & Total \\
\cline { 2 - 5 } & \multicolumn{2}{c}{$3+$} & $2+$ & \multicolumn{2}{c}{$1+/ 0$} & \\
Amplification & $14(100 \%)$ & $10(18.2 \%)$ & $0(0 \%)$ & 24 \\
No amplification & $0(0 \%)$ & $45(81.8 \%)$ & $100(100 \%)$ & 145 \\
Total & 14 & 55 & 100 & 169 \\
\hline
\end{tabular}

Figures 


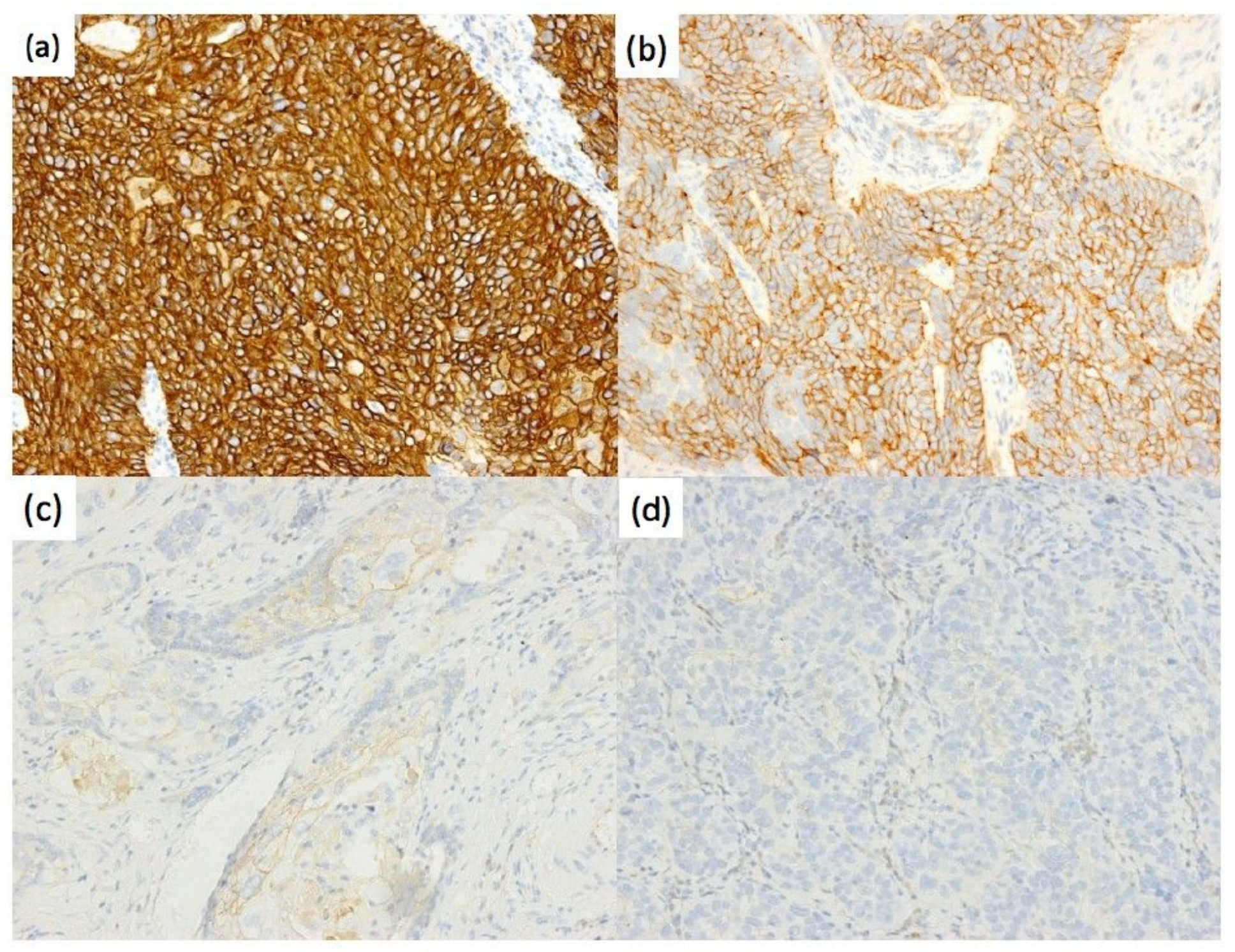

\section{Figure 1}

Immunohistochemistry showing HER2 expression in esophageal squamous cell carcinoma. (a) HER2 overexpression in tumor cells. Original magnification, 200x. (b) HER2 equivocal expression in tumor cells. Original magnification, 200x. (c) (d) HER2 negative expression in tumor cells. Original magnification, $200 x$. 


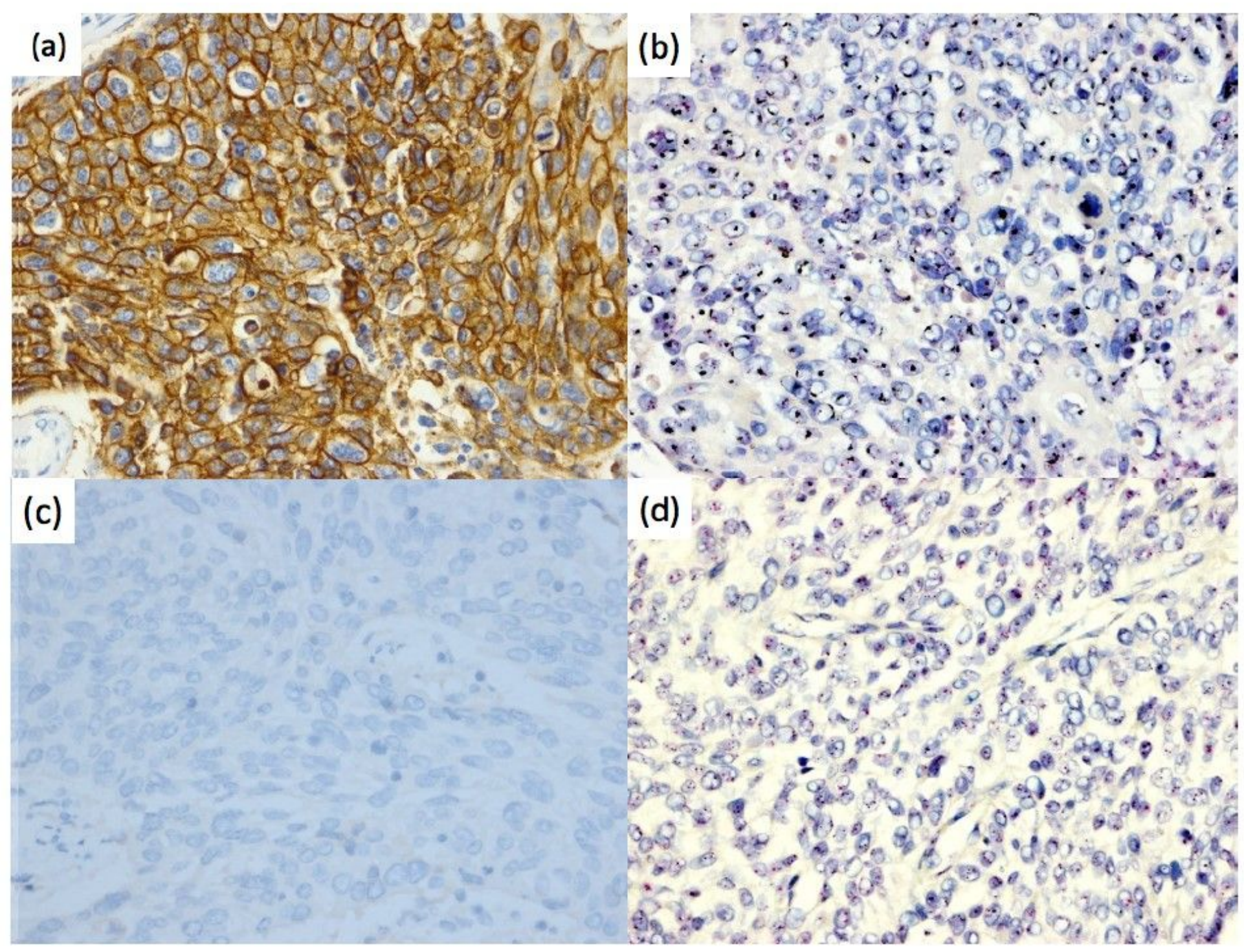

Figure 2

HER2 expression and amplification in esophageal squamous cell carcinoma by immunohistochemistry (IHC) and dual-color in situ hybridization (DISH). (a) HER2 overexpression in tumor cells based on IHC. Original magnification, 400x. (b) HER2 gene amplification in tumor cells based on DISH. Original magnification, 400x. (c) HER2 negative expression in tumor cells based on IHC. Original magnification, 400x. (d) Lack of HER2 gene amplification in tumor cells based on DISH. Original magnification, 400x. 